\title{
Ways of rational use of natural landscapes of the zarafshan mountains and adjacent plains
}

\author{
H. Zhurakulov*, D. Zhurakulova. E. E. Turaev \\ Samarkand State University, Department of Ecology, 140104 Samarkand, Uzbekistan
}

\begin{abstract}
A characteristic peculiarity of the landscapes of the Zarafshan Mountains and the adjacent plains is that their development is dependenton geographical zoning. According to the zonal features, the landscapes of the studied area are located in the desert zone.
\end{abstract}

\section{Introduction}

The study of the landscapes of the Zarafshan mountains and the adjacent plains showed that the natural conditions of the studied area are very diverse. Landscape complexes located in different parts of the district differ not only in their natural features, but also in their economic purpose. These differences are based primarily on the fact that the landscapes of the studied area developed under different natural conditions of relief, both flat and mountainous.

The development of the landscapes of the described area, located at different absolute heights. This creates different natural zones, such as semi-desert and dry-steppe. In each zone there are landscapes with different economic value. In addition, azonal landscapes are observed on flat landscapes, which differ in their humidification conditions

The mountain landscapes of Zarafshan are semi-desert, dry-steppe, steppe and sparsely wooded zones. The landscapes located in each zone also have their own economic values and differ from other landscapes located in another zone. Given this difference, the issues of rational use of the landscapes of the plains and mountains located in each zone are considered separately.

These maps, based on materials from field work and the results of analysis and generalization of literature data, served as the main compilation of a medium-scale landscape-typological map [1].

\section{Results}

Fig. 1 shows the landscape-typological map that we made as a result of field research and analysis of the work of other researchers [2-7].

\footnotetext{
*Corresponding author: boymurodov1971@mail.ru
} 


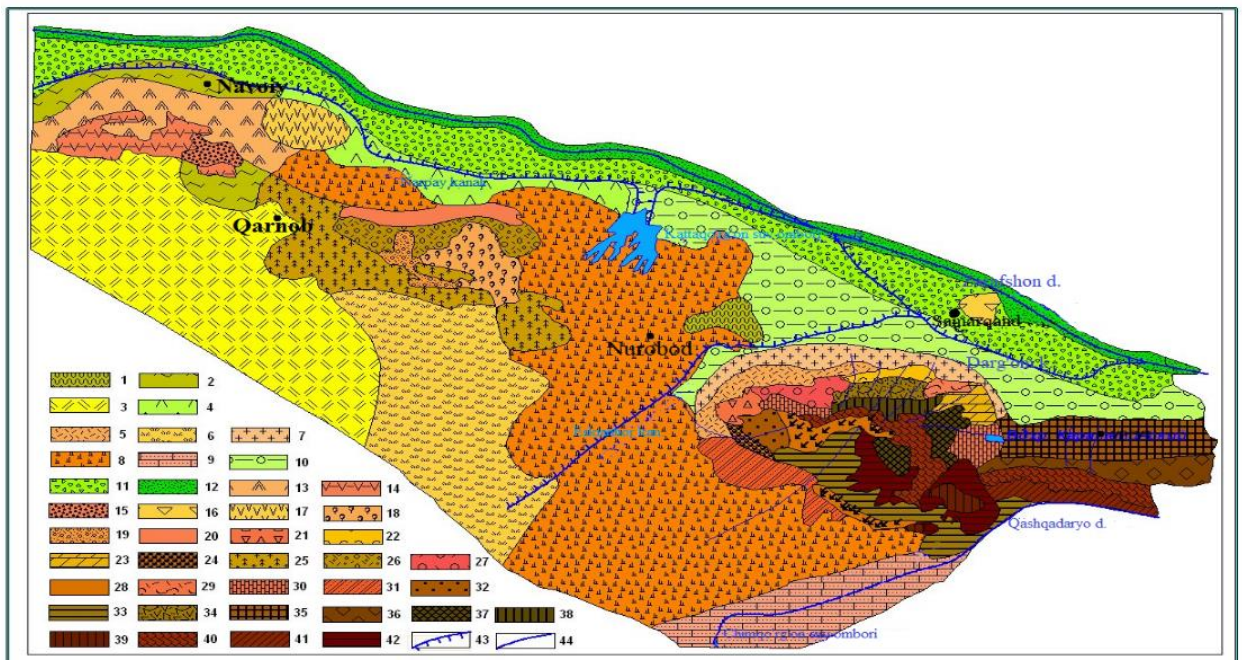

Fig. 1. Map of Landscapes of Zarafshan Mountains and Adjacent Plains. Author; H. Zhurakulov

\subsection{Legend}

\subsubsection{A class of flat landscapes. Zonal landscapes.}

Semi-desert type of landscape. Kinds: 1. Yantachno-ephemral on saline greyish soil sof large flat depressions of steep proluvial plains; 2. Ephemeral-sagebrush on light greyish soils of inclined denudation-accumulative proluvial plains; 3 . Ephemeral-sagebrush on light greyishsoilsof proluvial plains.

Dry-steppe view of the landscape. Kinds: 4.Sagebrush-ephemeral on light serozems of inclined denudation-accumulative proluvial plains; 5.Sagebrush-ephemeral on typical greyish soilsof inclined foothill proluvial plains; 6 . Sagebrush-ephemeral on typical greyish soilsof inclined proluvial plains; 7.Sagebrush-sarygul (wild rose) - ephemeral on typical greyish soils of inclined proluvial plains; 8.Mixed grass-ephemeral on typical gray soils of girder-uvalisty proluvial and large-uvalisty loess plains; 9. Variegated-sagebrush-ephemeral on meadow light gray soils of alluvial, slightly inclined terraced plains; 10.Sagebrushvariegated-ephemeral on typical gray soils of accumulative alluvial-proluvial plains.

Azonal landscapes.Meadow type of landscape. Species: 11. Mixed grass-legume-cereal on alluvial gray soils of alluvial, terraced plains. Forest and shrub landscape type. Type: 12 . Tugai forests and forest shrubs on alluvial soils of floodplains.

\subsubsection{Class of mountain landscapes. Zonal landscapes.}

Semi-desert type of landscape. Types: 13. Ephemeral-wormwood on stony light greyish soils of low mountains; 14.Prickly-wormwood on stony light greyish soilsof low mountains; 15.Kozykulak-sagebrush-ephemeral on light gray soils of low-mountain basins.Dry-steppe type of landscapes. Species: 16. Sagebrush-ephemeral with thornyastragal shrubs on typical greyish soils of low mountains and denudation-accumulative plains; 17. Sagebrush-ephemeral on stony typical greyish soils of low mountains and denudation-accumulative plains; 18.Sagebrush-kozykulak-bluegrass with prickly bushes on typical greyish soils of low mountain basins; 19. Sagebrush-motley-ephemeral on typical greyish soils of low mountain basins and valleys; 20.Sagebrush-grass-motley-prickly on 
stony typical greyish soilsof low mountains; 21.Astragalus-kozykulak-ephemeral on typical greyish soils oflow mountains; 22.Kozykulak-prickly-sagebrush-ephemeral on typical serozems of stepped foothills; 23.Prickly-sedge-bluegrass on stony typical greyish soils of low mountains; 24. Borodachevo-kolyuchemindalny on stony typical greyish soilsof low mountains; 25.Raznotravno-sagebrush-ephemeral with prickly shrubs on stony typical greyish soils of low mountains; 26.Raznotravno-bluegrass-sagebrush on stony typical greyish soilsof low mountains; 27.Multy grass-sagebrush-ephemeral with prickly almonds and hawthorn on typical greyish soils of low and medium mountains; 28. Multy grassprickly on stony typical greyish soils and brown soils of low and medium mountains; 29.Kozykulak-sarygul-sedge-bluegrass on stony typical gray soils of the stepped mountains.Steppe type of landscape. Types: 30.Kozykulak-thirny almond-bluegrass on typical greyish soilsof terraced sides of intra-mountain basins; 31.Kozykulak-bluegrass on dark greyish soilsof low mountains; 32.Bluegrass-legume-mixed grass on dark greyish soils of low-mountain basins; 33.Akkurai-legume-cereal with large-fruited hawthorn woodland on dark greyish soils of loess plains of intra-mountain basins 34.thorny- almond-sarygulbluegrass on dark gray soils of hilly-ridge low mountains; 35 . Thorny- almondraznotravno-bluegrass on dark gray soils of adyro-like low mountains and foothill denudation-accumulative proluvial plains; 36.Thorny almond multy grass-tipchak on stony brown settled soils of steeply sloping middle mountains; 37.Multy grass-bluegrass with prickly-almond shrubs on dark gray soils and brown leached settled soils.38. Multy grasswith prickly-thorny-hawthorn bushes and rare instances of juniper on stony brown sedimentary soils of the middle mountains; 39.Multy grass-bluegrass on brown sedimentary soils of leveled middle mountains; 40.Mixed-grass-tipchak on brown sedimentary soils of leveled watersheds of partially karst-covered middle mountains.Sparsely wooded and xerophytic-shrubby type of landscape. Species: 41 . Thorny-hawthorn woodlands on stony brown soils of the middle mountains; 42.Juniper woodlands and xerophytic shrubs on stony brown soils and outcrops of bedrock.Other : 43. Large irrigation systems.

\subsection{Landscapes of the plains.}

Semi-desert landscapes of the plains are located within the Karnab and Jam-Ulus foothill plains at an altitude of $225-280 \mathrm{~m}$ above sea level. The main territory of these landscapes is used as year-round pastures. Within the characterized landscapes, ephemeral-sagebrushamber phytocenoses are developed. Ephemeral-wormwood-amber phytocenoses are the most valuable feed for Karakul sheep for almost all year round. The food balance of the pasture area is based on ephemera in spring and summer, and sagebrush and yantak in autumn and winter. Ephemera are a good foot food during early spring grazing, as they are most well-supplied with nutritious plants and are less well-supplied in autumn and winter.

The research of the Karnab Research Institute of Karakul Breeding has shown that in a relatively short time, at low cost, it is possible to significantly increase the productivity of natural pastures by sowing forage plants and crops such as saxaul, izen, chogon, Cherkez, teresken and others. Black saxaul deserves special attention.

Long-term research by the staff of the Research Institute of Karakul-forestry and Desert Ecology of Uzbekistan has shown that artificial pastures created from a mixture of different species and life forms of natural plants (black saxaul, Richter's Circassian, chogon, teresken, izen, and others) are characterized by high and stable feed yields, providing fullfledged year-round pasture, feeding and keeping sheep.

Crop rotation systems are of great importance for preserving moisture in the soil on bogar. Here it is recommended to create a five-field row crop rotation. In the rowed wedge, alfalfa can be grown for hay and melons (watermelons). The yield of melons is $80-100 \mathrm{c} / \mathrm{ha}$. It should be noted that the territory of the Ulus landscape is the most promising area for the 
development of irrigated land. For further land development, the Yangi Aryk diversion channel was laid here. In addition, within the studied landscapes of the semi-desert zone, there are interplastic pressure waters (Nagornaya) with a temperature of $45^{\circ}$, currently used for the treatment of patients with rheumatism, osteochondrosis. It should be noted that the need for the population to treat this water is huge. Therefore, in order to use these interplastic waters for the treatment of patients, it is necessary to expand the hospital area and increase the number of beds. To improve the rest of patients, it is necessary to expand the area of green spaces around the hospital.

Dry-steppe landscapes cover the territory of the foothill plain located in the foothills of the Zirabulak-Ziadi, Karatepa and Chakylkalyan mountains at an altitude of 285-700 m above sea level. It should be noted that the main part of these landscapes is used as pastures. This is especially true for the landscapes located on the foothill plains of the Zirabulak-Ziadi Mountains and the northern and southern slopes of the Karatepa Mountains. The surface structure of the foothill plains located around the Zirabulak-Ziadi mountains is characterized by a dissected relief. Here, there are outcrops of bedrock with light, coarse-skeletal gray soils. The vegetation cover is represented by ephemera, sagebrush, and kozykulak. The landscape is used as spring, autumn and winter pastures.

I must say that part of the landscapes of the foothill plains is subject to irrigation. Such landscapes are located on the Pridargom foothill plain, located on the northern slope of the Karatepa Mountains. The consistency of the slopes from the foot of the mountains to the valleys provides a good surface runoff. When irrigating land, hydrogeological and reclamation conditions will be favorable everywhere due to the large depth of ground water. Some areas of the foothill plains landscape that are suitable for irrigation are currently in a neglected state. To increase the productivity of these landscapes, it is necessary to start fighting surface and gully erosion. For this purpose, it is recommended that deep plowing (up to $35-40 \mathrm{~cm}$ ) should be carried out against surface linear or planar erosion on soils with a thick low-earth layer, which contributes to the cessation of surface runoff of atmospheric precipitation. Within this landscape, ravines are widely developed, especially near the Dargom Canal. To stop the development of ravines, it is recommended to create forest strips, and fast-acting ravines should be fixed with engineering structures.

It should be noted that part of the landscapes of the foothill plains is used for bogara. Such landscapes are particularly well developed within the western and southern extremities of the Karatepa Mountains. The typical greyish soils present here have a fairly strong transverse horizon with a humus content of $2.2 \%$, and phosphorus content of 0.16 $0.17 \%$. These soils are characterized by a fairly high fertility in terms of their physical and chemical composition, and can be used for various agricultural crops. They are currently used under bogaru. The main activities should be directed here to preserve moisture. To do this, it is necessary to carry out plowing in the fall. Autumn plowing protects more moisture, improves the physical properties of the upper horizons, accumulates more nutrients, and so on. This landscape is suitable for irrigation and the Yangi Aryk canal, an outflow of the Zarafshan River, is laid for this purpose.

Azonal landscapes. Located within the first, second, third and partially fourth floodplain terraces of the left bank of the Zarafshan River and the right bank of the Kashkadarya River from 225 to $700 \mathrm{~m}$ in absolute height. Currently, the described landscapes are fully developed and used for irrigated agriculture.

The landscapes of the terraces of the Zarafshan and Kashkadarya valleys have been greatly changed and turned into oasis landscapes as a result of centuries-old human activity. Artificial irrigation of the landscape has been carried out for more than 3000 years. Centuries-old artificial irrigation in the Zarafshan valley led to the formation of a new rather powerful (1-2 m) agro-irrigation horizon. The waters of the Zarafshan River contain a lot of nutrients, both in solid and in soluble form. It should be noted that the landscapes 
located on the first, second, third and fourth above-floodplain terraces are drained, with irrigated loamy and sandy loam meadow and meadow-swamp soils. Therefore, the landscapes of these lands are of great economic importance, they contain the main arrays of horticulture and other agricultural crops.

It should be noted that down the Zarafshan River, within the terraced plains landscapes, an increase in soil salinity also begins in the Kattakurgan area. Salinization is of a sulfatechloride nature. The main cause of soil salinization is the close occurrence of groundwater. To increase the depth of ground water, it is necessary to build a collector and drainage network. To provide water to the irrigated lands in the lower part of the Zarafshan Valley (Kattakurgan, Narpai districts), the Kattakurgan reservoir with a volume of $840 \mathrm{mn} \mathrm{m} 3$ of water was built here.

Forests and shrubs cover the landscapes located in the floodplain of the Zarafshan River. These landscapes are mainly occupied by tugai forests. The type of tugai vegetation combines not only woody, but also grass and shrub communities of river valleys, which are closely related in their origin to the development of the ecological conditions of these valleys. Genetically related and ecologically close communities of the tugai type differ in the structure and features of the edifiers. This makes it possible to divide them into three groups of formations, such as tree-shrub tugai, shrub-tugai and herbaceous-tugai. All these three species developed within the floodplains of the Zarafshan River valley have been declining sharply in recent years.

The land previously occupied by Tugai is being developed for agricultural crops and allocated for the construction of residential buildings. In this regard, in recent years, the area occupied by tugai landscapes has been sharply reduced. In the future, it is necessary to expand the area of tugai landscapes. In addition, the tugai landscapes are a great place to relax. Certain works have been done on the use of tugai landscapes as recreation areas. Near the Chupanata and Akdarya Bridge on the floodplains of the Zarafshan River, two artificial lakes have been built - "Light Lake" and "Seven Lakes", where the population of the city of Samarkand spends their time on Sundays [1].

\subsection{Mountain landscapes.}

Semi-desert landscapes reach significant heights in the Ziadi Mountains - $868 \mathrm{~m}$ above sea level. Within the landscape there are sections of dissected steep mountain slopes. On such landscapes, the slopes are almost bare, devoid of vegetation. Only in some parts of the mountain slopes, as well as in the valleys of the mountain sais, on light gray soils, there is sagebrush-ephemeral vegetation with an admixture of prickly almond bushes. They are used as spring and summer pastures. The landscape is unproductive. It is necessary to prohibit the harvesting of prickly almonds for fuel.

The westernmost extremities of the Ziadin Mountains have a cuesta character. Here, in the inter-cuesta depressions and sayas, in the spring time, water accumulates, flowing down from the slopes of the cuesta ridges and mountains, and underground water lies shallow from the surface. The soils are favorable for the growth of solyanka plants. The landscape is used as pasture.

The main part of the landscapes of the Ziadin Mountains is represented by latitudinalelongated beds composed of sandstone and shale. Between these beds there is a weakly dissected hilly surface on granites. Here, on gravelly, sometimes eroded light gray soils, sagebrush-ephemeral vegetation is developed. The landscape is used as pasture.

Dry-steppe landscapes cover the main part of the Zirabulak Mountains and the lowmountain part of the northern slope of the western tip of the Karatepa Mountains. These landscapes are located at an altitude of $700 \mathrm{~m}$ in the west and $1700 \mathrm{~m}$ in the east. The main part of the landscape of the Zirabulak Mountains consists of widely elongated ridges. These 
ridges mainly occupy the peripheral part of the mountains. The central part of this landscape is a hilly platelike surface composed of granites. Within the intermountain depressions, there are mountain ais that are shallow and wide. The main part of the plateaulike upland and the slopes of the ridges are covered with typical fine-grained gray soils with sagebrush-ephemeral vegetation. They are used as pastures, and of good quality. Within the landscapes of the Zirabulak Mountains, there are permanent watercourses in some sayas.these sayas contain orchards and vineyards. It should be noted that in the studied landscape, most of the mountain sais are waterless in summer and autumn. However, they form a runoff in winter and spring. Using these flood waters, it is possible to significantly expand the area of orchards and vineyards. In the low-mountain landscape on its southern slopes there are latitudinal-elongated rocky ridges, devoid of soil and vegetation, on the slopes of the mountains there are rare thorn bushes. The relief of the low-mountain landscape of the northern slope of the Karatepa Mountains and its western tip is characterized by a dissected hilly-ridge low-mountain with low-power stony, typical gravelly coarse-skeletal gray soils. There are often observed outcrops of bedrock. The vegetation cover is represented by ephemera and ephemeroids, summer-growing coarse grass (eremerus, flomis, and others), and almond bushes on stony slopes. The landscape is used as pasture. For the purpose of rational use of landscapes, it is necessary to accelerate the afforestation of the slopes of the low mountains. However, artificial afforestation should be carried out, as a rule, not on the periphery of the landscapes, but in the upper part and not in solid massifs, but in forest-belt plantations. For strip landings, the most droughttolerant breeds are recommended: ailanthus, pistachio, almond, white acacia. Within this landscape, the bottoms of the mountain sais expand sharply and there are developed alluvial, irrigated alluvial, loamy, sandy loam soils. Although they occupy very limited territories, this does not reduce their national economic importance. They are almost completely developed and used for vegetable gardens, orchards, vineyards, etc.

For the rational use of this landscape and adjacent territories, the following measures are recommended: capting of springs and their periodic cleaning to improve the use of mountain river waters; retention and full regulation of spring flood runoff by creating reservoirs in large sayas. In the lower reaches of the Amankutan River, the Karatepa reservoir has been built with a useful capacity of 18 million $\mathrm{m} 3$, which makes it possible to irrigate large areas of land. In addition, in the future, it is advisable to build reservoirs (socalled selekhranilishcha) in Akkurgansay, Gijduvansay, Kamangaransay. The construction of water storage facilities will allow to accumulate spring floods and irrigate several thousand hectares of land in the landscapes of the foothill plains.

To improve the productivity of these landscapes, it is necessary, first of all, to abandon the sowing of annual agricultural rainfed crops, because annual plowing leads to the development of erosion. In addition, the use of live traction and manual labor at the current stage of agricultural development is environmentally unprofitable. The most appropriate and environmentally beneficial development of rain-fed viticulture and horticulture. In addition, the main part of this landscape is now developed and used for tobacco crops.

Among the dry-steppe landscapes in the interfluve of Zarafshan and Kashkadarya, the landscape of the Chupanataupland differs in the nature of its use. This landscape is located near the city of Samarkand. Currently, the lower parts of the slopes are used for forest plantations. A recreation area for the workers of the city of Samarkand is organized on the artificially created woodlands. Part of the territory of the Chupanatahill is used for obtaining construction materials. The Paleozoic sand-shale materials available here are used to produce crushed stone, as well as household material - for individual construction. Part of the territory of the Chupanata hill is used for the construction of public buildings. It only requires a more rational combination in the placement of these lands. 
Steppe landscapes are located on the slopes of the Karatepa and Chakylkalyan mountains, at an altitude of 1700-2800 m above sea level. The surface of the landscapes is divided by the valleys of mountain rivers and sais. The valleys here are mostly dry, the slopes are steep and are occupied to varying degrees by washed-out stony-gravelly soils under mixed-herb-ephemeral semi-shrubby and shrubby plants. Meets archa. The landscape is used as a summer-autumn pasture.

Thus, one of the important issues of increasing the productivity of the steppe landscape of steeply sloping middle categories is the fight against soil erosion. Methods of combating soil erosion and mudflows are mainly developed and justified by the employees of Central Asia A. Abdulkasimov [2]. For the landscape under consideration, the most reliable and proven means of regulating surface runoff, stopping or weakening erosion-mudflow flows, is afforestation and terracing.

Terracing slopes, radically changing the conditions of the runoff surface, can eliminate soil erosion in a relatively short time, improve the hydrogeological regime of the slopes, and provide the prerequisites for more successful afforestation of mountain areas. This is clearly evidenced by the experience of carrying out such works at the Amankutan forest dacha. Mountain forest stands fasten the soil with roots, increase water filtration, transfer surface livestock to underground, reduce the amount of flowing water and its speed, thereby weakening erosion processes. According to Eshkuvvatov [6], due to the delay of surface runoff, water seepage into the soil, mountain forest stands retain up to $50 \%$ of all precipitation. The steeper the slopes, the more noticeable the influence of the forest. The increase in water filtration in the forest soil leads to the replenishment of underground water reserves, which is confirmed by the large number of springs in forest areas. So, on the territory of the Amankutan forest dacha, thanks to forest plantations, the number of springs has increased. For example, on the Tashkent-Termez road in the area of the pass there were only two springs, and there were about six.

The steppe landscapes of Chakylkalyan and Karatepe are mainly used as pastures. As a result of the lack of proper care of pastures and non-compliance with the rules of operation, large areas of them are knocked out by cattle and are subject to erosion. Therefore, it is necessary to regulate pastures, apply a corral grazing system and pasture rotation. For each pasture area, depending on the yield of the eaten mass, the norms of the load of livestock should be established, grazing should be temporarily stopped on heavily knocked-out areas so that by sowing valuable grasses and applying a small amount of fertilizers, they can be turned into high-yielding pastures. In addition, the improvement of forest protection, the prohibition of unplanned cutting of shrubs, the determination of the path of cattle driving of watering places, the strengthening of scree and placers, the construction of catchment structures - selekhranilishch, collecting tracts for mudflow and storm water give good results. Observations have shown that within the forest landscapes of the described mountains, the local population annually harvests a large amount of rhubarb(rhubarb). As a result of the haphazard collection of rhubarb, its distribution areas are now sharply reduced. Therefore, it is now necessary to raise the issue of the protection of this valuable culture.

Sparse woodlands and xerophytic shrubs are found on the southern slope of Chakylkalyan and at the junction between Chakylkalyan and Karatepe in the area of the Takhta-Karacha pass. It should be noted that in the past, forests and shrubs within the described mountains were widespread. Currently, due to their cutting down for fuel, as well as the use of woodlands for pasture, the area of these woodlands has been greatly reduced. Nevertheless, the water and soil protection role of these forests is huge. Therefore, in the future, these forests should not be allowed to be cut down and they should be taken under protection. 


\section{Conclusion.}

The study of the types of landscapes between the Zarafshan and Kashkadarya rivers showed that the landscapes of the studied area are characterized by a significant degree of sedimentation. This is due, along with the general climatic conditions, to human economic activity.

Improper use of landscapes - excessive grazing of livestock in certain areas of the landscape, cutting down of trees and shrubs

vegetation for fuel and the destruction of undergrowth as a result of cattle grazing in juniper forests, a violation in the crop rotation system, and so on-led to their strong settling down.

To prevent the negative consequences of anthropogenic impact on the landscapes of the Zarafshan Mountains and adjacent plains, we have proposed the following measures::

1. Conduct an inventory of the plains and mountain landscapes of the described area in order to identify degraded landscapes;

2.In degraded landscapes, plant seeds (wormwood, izen, chogon, keireuk, and others) should be sown. To carry out also plantings of black saxaul and to create forest strips; 3 . Within mountain landscapes to carry out terracing of slopes and planting of tree and shrub vegetation; 4.In the landscapes used under rain-fed agriculture, all agrotechnical measures should be directed to preservation of moisture in soils. To do this, it is necessary to carry out autumn plowing, create forest strips where strong winds are observed, apply steamtilled crop rotations, as well as fertilize plants with mineral and organic fertilizers; 5 . In landscapes used for irrigated agriculture, it is necessary to combat water and wind erosion, soil salinization, and so on. For this purpose, it is necessary to plan the fields, avoid watering, where there are large slopes. On such lands recommend planting vineyards;

\section{References}

1. A. Abdulkasimov, X. Zhurakulov, Regularities of differentiation of landscapes of the Zarafshan mountains and adjacent plains (Samarkand, 2014)

2. A. A. Abdulkasimov. et al., Anthropogenic landscapes of Central Asia and environmental issues (Tashkent, 2004)

3. A. A. Abdulkasimov, Sh. M. Akhmedov, B. A. Meliev, Differentiation of mountain and foothill-plain landscapes of the Zarafshan basin. (Andijan, 2012)

4. L. A. Alibekov, Landscapes and types of lands of the Zarafshan Mountains and adjacent plains. (Fan., Tashkent, 1983)

5. X. Zhurakulov, Scientific Bulletin, 28, 64-67 (Tashkent, 2007)

6. B. Eshkuvvatov, Assessment of foothill plains and landscape complexes for microdistricting and economic purposes. Abstract of the PhD dissertation in geographical sciences. (Samarkand, 2020)

7. M. G. Nazarov. Anthropogenic landscapes of the Kashkadarya basin and their geoecological state. Abstract of the PhD dissertation in geographical sciences (Samarkand, 2020) 